\title{
The innovation application on Batik craft products in the New Normal Era in Indonesia: Does it have an impact?
}

\author{
F. Ciptandi \& M.S. Ramadhan \\ Telkom University, Bandung, Indonesia
}

\begin{abstract}
The purpose of this study is to find out whether the new normal era set by the Indonesian government has an impact on efforts to apply innovation in handicraft products to batik craftsmen. The traditional batik industry in Tuban, East Java was chosen as an example of a case because it is considered to represent other traditional batik industries in Java Island. In the previous study, the strategy of applying the innovation for batik has been carried out successfully using the diffusion of the innovation theory approach by providing an experimental assignment of the innovation application. This study was conducted by analyzing the factors considered as a source of inhibiting the transfer of innovation and its impact using a combination of the design thinking approach and diffusion of innovation ideas. This is useful as one of the solutions today to prepare for the continuation of innovation in the midst of the post-COVID-19 pandemic.
\end{abstract}

Keywords: innovation, batik, craft, COVID-19

\section{INTRODUCTION}

COVID-19 positive patients in Indonesia continue to increase. Responding to this condition, the Indonesian government has implemented several policies to anticipate the wider spread of the virus, ranging from physical distancing, a temporary ban on entry into Indonesia, to large-scale social restrictions.

It was only on May 28, 2020 that the Central Government through the Minister of National Development Planning/Head of Bappenas, in a joint press conference with the Foreign Minister as well as the Task Force Team of experts handling COVID-19, presented the Productive and Safe Community Protocol COVID-19 designed to create a new normal to coexist with COVID-19 (Hadi \& Supardi 2020). It also targeted several economic activities that were previously stopped and will begin to be reactivated gradually by following the health protocol requirements. However, this condition still has a significant impact on various economic sectors, including the batik handicraft sector.

Since the implementation of the new normal era in Indonesia, the batik handicraft industry sector can no longer stand by the old patterns that have become a comfort zone. In addition to taking part in thinking about practical steps according to health protocols to reduce the spread of the COVID-19 virus, efforts to innovate quickly and precisely in shaping the craftsmen's new behavior in order to compete and survive also need to be considered (Ciptandi 2020).

Innovations, according to this new vision, have been applied in the traditional batik handicraft industry in Kerek District, Tuban Regency, East Java, which was chosen as an example of a case representing other traditional batik industries on Java Island, Indonesia. In 2018, the strategy of applying innovations in batik handicraft products in Tuban was carried out in the conditions before the COVID-19 pandemic and had obtained results, namely: (1) development of the visual appearance of Tuban batik patterns; (2) application of Tuban batik to the appropriate fashion products; and (3) improvement of creativity and the ability to adapt innovations for batik craftsmen. Based on this study, it has been concluded that the batik handicraft industry in Tuban has the ability 
to adapt well to innovation and has proven by experimental results to be able to produce several innovative designs (Ciptandi 2018).

There is a problem when innovation is to be given to traditional batik in Tuban continuously, which is currently in a new normal condition. In the protocol set by the government, generally, they still have to pay attention to physical distancing, where people are required to keep a distance from others by at least 1 meter and minimize crowding activities and prioritize activities carried out independently from home. At the same time, one of the stages in the diffusion of the innovation approach is persuasive communication from the innovation provider to the batik craftsmen/innovator. In addition to adjusting to the usual communication patterns in the Tuban environment, the other important step is that communication must be carried out intensively and personally by minimizing the distance between the innovation provider and the innovator, especially when conducting experiments together.

\section{METHODOLOGY}

This research was conducted by analyzing the factors inhibiting the transfer of innovation and the impact by combining the design thinking approach and the diffusion of innovation theory ideas. The diffusion of innovation is used for analysis in the form of communication channels that can be applied as an alternative to persuasive communication (Roger et al. 2019; Chia \&Garrett 2010). Design thinking is used at the same time to analyze the risk factors of implementing an innovation during these new normal conditions.

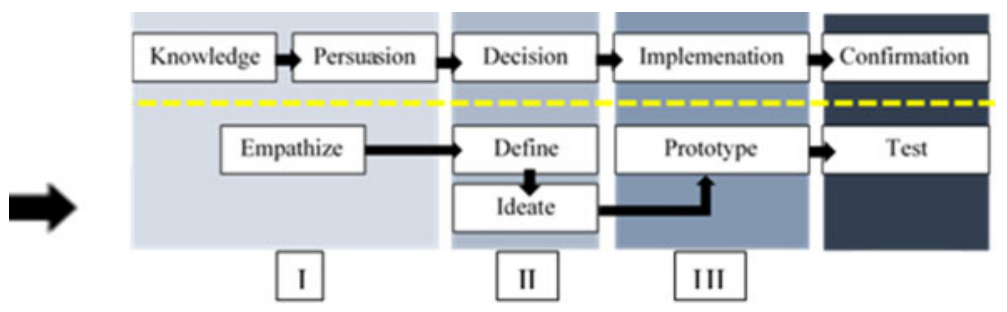

Figure 1. The combination of the design thinking approach and diffusion of innovation idea.

The analysis is done by grouping it into three stages.

1. Stage I: Motivation. It is encouragement that can be a driving force for recipients to accept the challenges of innovation, ranging from the characteristics of the recipient, problems in environmental conditions and social systems, as well as the basic needs of the recipient that must be met and analyzed for the impact of the risks.

2. Stage II: Creativity. It is the origin of ideas and analyzing the impact of the risks so that they are likely to be accepted or rejected.

3. Stage III: Implementation. It is a recommended implementation strategy in the form of a method and prototype, as well as an analysis of the impact of the risks.

\section{DISCUSSION}

Measuring the extent of the impact of conditions in the new normal era of COVID-19, by the process of applying innovation in the development of motifs on traditional batik crafts in Tuban, was carried out in accordance with Figure 2.

\subsection{Motivation stage}

Motivation factors as a driver for innovation to be possibly carried out, including: (1) recipient characteristics, namely Tuban people; (2) Tuban social system variables; and (3) community needs 


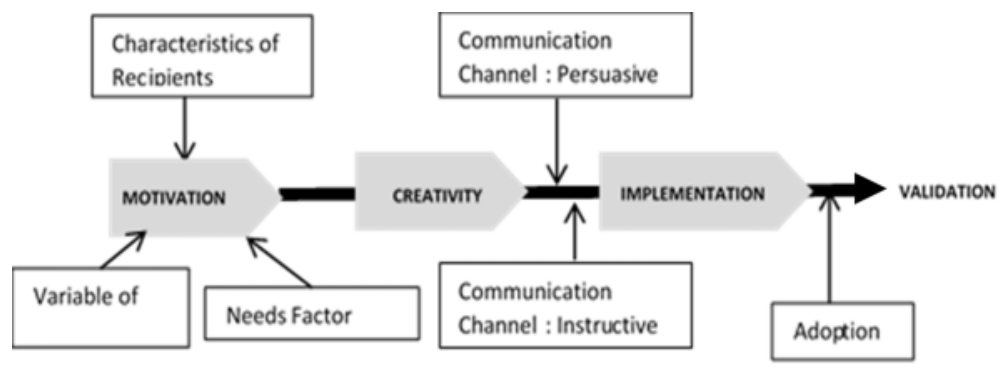

Figure 2. Analysis process of applying innovation of motifs development.

factors. The three motivational factors are analyzed based on the risks that might have an impact due to conditions in the new normal era, including:

1. Problem. In terms of characteristics, Tuban people are generally categorized into three mentality groups: (1) traditional; (2) moderate; and (3) modern. Based on the numbers, it is dominated by groups with moderate mentalities who have problems about how to interact with innovators who represent modern mentalities and traditional craftsmen who represent traditional mentalities. Additionally, the social system also presents problems in the form of interpersonal relationships that are stretched because they are overshadowed by feelings of fear and anxiety by the COVID19 case. Then, the economic problems were caused by a decrease in market demand, so that production activity declined and product design development activities were stopped.

2. Opportunities. There are still opportunities that can be optimized, namely by targeting Tuban community groups who have a moderate and modern mentality to become open to change again. The attitude of the people with this mentality tends to be open to change and optimistic as proven in previous studies that have succeeded in creating various design developments. In addition, another opportunity is that encouragement to economic needs will force a person to continue to make an effort to continue his/her living.

The motivational stage in the new normal era can be focused on Tuban groups with a moderate mentality. The drive of motivation is supported more by the issue of how the production process does not stop for an economic turnaround.

\subsection{Creativity stage}

The creativity stage is carried out to develop the design of traditional batik handicraft products starting from the process of identifying, discussing, to prototyping (Tung 2012) and taking into account the conditions in the current new normal era, including the following.

1. Identifying. At the motivation stage, it has been concluded that innovation can be applied to community groups with a moderate mentality with the greatest motivation driven by economic needs. Furthermore, at the identifying stage, it is necessary to make a comprehensive thought process about what can be offered as a solution.

2. Discussing. At this stage, the researcher or designer needs to have a discussion by involving several parties outside himself, to get input for ideas so that the decisions taken will not be subjective.

3. Prototyping. At this stage, the results can be in the form of product prototypes or strategy recommendations in the form of methods that can be done to realize creative ideas that can be applied by craftsmen (Trussler \& Beckett 2016), especially under the conditions of (the) new normal era.

At this stage, the biggest challenge is to formulate the problem to come to the right needed solution. The risk of this stage is that the results, offered as a solution, do not have an absolute 
measure of success. Moreover, especially in the conditions of the new normal era, there are new conditions that have not been experienced before, either by the innovator or the adopters, so that in the identifying stage, it is necessary to conduct research on the characteristics and effects of conditions in this new normal era. The key to success at this stage is an understanding of the characteristics of the conditions of the new normal era and the influence on people's needs.

\subsection{Implementation stage}

The implementation stage is the process of implementing solutions resulted (resulting) from the creativity stage. In the conditions of this new normal era, this implementation stage is closely related to communication channels.

The communication channel consists of two things, the first is persuasion, which is the most influential in transferring innovation to craftsmen, especially because in new normal conditions there are distance restrictions and frequency limits for meetings that are intense. Therefore, with this condition, there is a distance that slows the process of transfer of innovation through communication. This not only happens between innovators to innovator craftsmen but also from innovators to other adopters. Other communication channels are instructive, which is a communication form carried out to provide work instructions in the form of experimental assignments to craftsmen.

The thing that has the most impact on changing conditions entering the new normal era is the communication channel. Communication patterns that were previously intense and personal must be slowly changed with the communication model by involving third parties as a connector of information. These third parties can be selected from the indigenous Tuban community groups who represent a modern mentality that is accustomed to online communication patterns both via mobile phones and other online platforms.

It is also necessary to anticipate the possibility of risks that will arise, one of which is the received information that is misunderstood, so that the resulted (resulting) form of innovation is not achieved. To minimize this condition means to always carry out repeated confirmation processes to ensure the information provided has been received correctly, and to communicate more frequently, at least double the number of common communication frequencies (Fogg 2009).

\section{CONCLUSIONS}

This study resulted in several considerations in conducting innovation to traditional batik handicraft products in the midst of the new normal era of COVID-19, i.e., first by identifying the factors inhibiting the transfer of innovation and risk factors by using a combined approach of design thinking and diffusion of innovation theory ideas. The results of the analysis include the following.

1. The motivation stage can be focused on the Tuban community group with a moderate mentality and the motivation can be lifted from the issue of economic needs.

2. The creativity stage needs to strengthen the identifying process to understand the characteristics of the conditions of the new normal era and the influence on the needs of the community and be open to receive suggestions and input from parties outside the designer/researcher. This process needs to be done in-depth and not in a hurry so that it can be more precise in continuing the prototyping process.

3. The implementation stage is carried out by changing the communication model with the involvement of third parties as a connector of information from the Tuban native community group that represents a modern mentality and is accustomed to online communication patterns. In this type of online communication, it is also necessary to repeat the confirmation process with more frequencies, at least double from the usual number of communication frequencies.

In the final stage, there is a validation stage which is a process of measuring the level of success in realizing an innovation idea given by the innovator. This stage can be developed in further research. 


\section{REFERENCES}

Chia, C. F. and Garrett, T. C. 2010. Diffusion of Innovations Theory, in Handbook of Research on Contemporary Theoretical Models in Information Systems 242-276. IGI Global.

Ciptandi, F. 2020. Strategies for improving workers' skills through crafts product innovation, Int. J. Psychosoc. Rehabilitation 24(7):8295-8301.

Ciptandi, F. 2018. Transformation on Design of Gedog Weaving and Traditional 'Tuban' Batik Decoration Through Visual Characteristic Experiment, Institut Teknologi Bandung: Indonesia.

Fogg, B. 2009. A Behavior Model for Persuasive Design, Proc. Intern. The 4th International Conference on Persuasive Technology - Persuasive 2009. New York.

Hadi, S. and Supardi. 2020. Revitalization Strategy for Small and Medium Enterprises after Corona Virus Disease Pandemic (Covid-19) in Yogyakarta, J. XI'AN Univ. Archit. Technol 12(4).

Rogers, E. M., Singhal, A., and Quinlan, M.M. 2019. Diffusion of Innovations 1, in An Integrated Approach to Communication Theory and Research, 3rd ed. 415-434. Routledge.

Trussler, H. S., Sharp, and Beckett, R. 2016. Innovation through craft: Opportunities for growth, 1 st ed. Craft Council: United Kingdom.

Tung, F. W. 2012. Weaving with rush: Exploring craft-design collaborations in revitalizing a local craft, Int. J. Des. 6(3):71-84. 